difference is not necessarily due to a motivational difference existing between these two conditions but rather, due to an informational difference. That is, subjects in the "right" condition often incorrectly interpret no comment by the experimenter as meaning "right," while subjects in the "wrong" condition are correct in assuming that no comment by the experimenter means "right." Spence's research indicates that the performance difference between these knowledge of results conditions does not occur if subjects receive explicit instructions as to what information the absence of comment by the experimenter will provide regarding the correctness of subject's response. The present failure to find a reliable knowledge of results effect could have resulted from the fact that the preceding condition held, due to the wording of the instructions used. In addition, another possibility is that the ability of the subjects to make the correct inference regarding the meaning of no comment by the experimenter is related to their developmental level, and that these ninth graders were able to correctly deduce the meaning of no feedback in the "right" condition.

\section{REFERENCES}

Buss, A. H., \& Buss, E. H. The effect of verbal reinforcement combinations on conceptual learning. Journal of Experimental Psychology, 1956,52, 283-287.

Caron, R. F., \& Caron, A. J. Motivation as a determinant of retroactive inhibition. Journal of Verbal Learning and Verbal Behavior, 1965, 4, 17-24.

Curry, C. The effects of verbal reinforcement combinations on learning in children. Journal of Experimental Psychology, $1960,59,434$.

Horwitz, L. M. Free recall and ordering of trigrams. Journal of Experimental Psychology, 1961, 62, 51-57.

Kernoff, D., Weiner, B., \& Morrison, M. Affect and short-term memory. Psychonomic Science, 1966, 4, 75-76.

Peterson, L. R., \& Peterson, M. Short-term retention of individual verbal items. Journal of Experimental Psychology, $1959,58,193-198$

Spence, J. T. Verbal discrimination performance under different verbal reinforcement combinations. Journal of Experimental Psychology, 1964, 67, 195-197.

Spence, J. T. \& Dunton, M. C. The influence of verbal and nonverbal reinforcement combinations in the discrimination learning of middle- and lower-class preschool children. Child Development, 1967, 38, 1177-1186.

Spence, J. T. \& Segner, L. L. Verbal versus nonverbal reinforcement combinations in the discrimination learning of middle- and lower-class children. Child Development, 1967, 38, 29-38.

Warner, W. L., Meeker, M., \& Eels, K. Social class in America. Chicago: Science Research Associates, 1949.

Weiner, B. Effects of motivation on the availability and retrieval of memory traces. Psychological Bulletin, 1966a, 65, 24-37.

Weiner, B. Motivation and memory. Psychological Monographs, $1966 \mathrm{~b}, 80$, Whole No. 626 .

Weiner, B., \& Walker, E. L. Motivational factors in short-term retention. Journal of Experimental Psychology, 1966, 71, 190-193.

(Received for publication October 3, 1974.)

Bulletin of the Psychonomic Society

1975, Vol. 5 (1), 81-83

\title{
Semantic differential ratings of impoverished stimuli: A replication
}

\author{
HARVEY K. BLACK \\ State University College of New York at New Paltz \\ New Paltz, New York 12561
}

\begin{abstract}
Pictorial stimuli that progress through varying degrees of clarity were rated on semantic differential scales. As the stimuli approached clarity, they were rated more positively as well as more active and potent. Positive evaluation of clear stimuli agrees with Draguns's (1967) findings: results with respect to potency and activity are opposite in directon. The significance of the present findings with regard to motivational properties of impoverished stimuli is noted.
\end{abstract}

The examination of the properties of impoverished or ambiguous stimuli has been conducted by a number of investigators in a variety of ways. Frohlich and Laux (1969) found tachistiscopic exposure, which itself progressed from extreme ambiguity to clarity, of a series of stimuli, resulted in increases in skin conductance level. Also using psychophysiological methods, Beyn, Zhirmunskaya, and Volkov (1967) found alpha depression in the EEG records of those who viewed

This paper is sponsored by Charles N. Cofer who takes full editorial responsibility. tachistiscopically presented stimuli, which consisted of pictures of a variety of common objects.

Employing a different dependent measure, the semantic differential, Draguns (1967) also found evidence of heightened arousal, as well as negative evaluation, connected with impoverished stimuli. As these stimuli, presented in booklet form, approached clarity they were rated as being less potent, less active, and more positive. The more visually impoverished the stimuli, the more potent, more active, and less positive were the ratings. 
Table 1

Ratings on Semantic Differential Scales of Pictorial Stimuli Differing in Clarity

\begin{tabular}{llrc}
\hline Scale & Factor & F Ratio & p Value \\
\hline *Nice-Awful & Evaluation & 16.50 & .001 \\
*Clean-Dirty & Evaluation & 8.75 & .001 \\
*Pleasant-Unpleasant & Evaluation & 15.82 & .001 \\
*Good-Bad & Evaluation & 12.20 & .001 \\
*Important-Unimportant & Evaluation & 3.06 & .02 \\
*Tense-Relaxed & Activity & 3.33 & .01 \\
*Large-Small & Potency & 3.65 & .01 \\
*Heavy-Light & Potency & 3.18 & .02 \\
*Strong-Weak & Potency & 8.29 & .001 \\
\hline
\end{tabular}

Note-The direction of trend is $C>U$.

${ }^{*}$ Denotes the numerically higher end of the scale.

${ }^{* *} C$ denotes clear, $U$ denotes unclear.

Thus, interest in the motivational effects of reduced stimulus input represents an area of rather widespread interest, as indicated by the variety of methodologies used in its exploration as well as by the diversity of the investigators in the area. The present study, which attempted to replicate Draguns's findings, is the first of a series whose goal is to examine physiological processes connected with attending to impoverished stimuli and to explore personality differences associated with the ratings of such stimuli. A subsidiary purpose was the exploration of the feasibility of presenting these stimuli in the form of photographic slides, instead of the booklet form used by Draguns.

\section{METHOD}

\section{Subjects}

Subjects were 20 students from introductory psychology classes at the State University College of New York at New Paltz.

\section{Procedure}

Each subject was examined individually. Subject sat in a darkened room behind a small table on which was placed a Kodak 800 Carousel projector. The slides were projected onto a white wall between 2 and $3 \mathrm{ft}$ in front of subject. The slide projector was operated by the experimenter using the remote control switch on the projector. As each slide was projected, the subject rated it on each of 14 semantic differential scales. These scales were identical to those used by Draguns.

Nine series of 12 slides were available. Each series depicted a common object whose likeness gradually became clearer over the 12 -slide progression. A slide may be regarded as a different stage of clarity.

In a given experimental session, four series were used. From each series, five slides were projected, representing the first, third, sixth, ninth, and twelfth stages of clarity. Each group of five were presented in order of increasing clarity. The four series used varied across experimental sessions as did each series's position.

In summary, each subject rated four slides at each five states of clarity, i.e., a total of 20 slides.

\section{RESULTS AND DISCUSSION}

Ratings of the slides on each of the 14 semantic differential scales were analyzed by repeated measures ANOVA's as well as by trend analyses described by Keppel (1973). Ratings on nine of the scales attained acceptable levels of significance. These results are summarized in Table 1. Ratings on five scales failed to attain significance. These scales, and the factors on which they load were: beautiful-ugly (evaluation), hot-cold (activity), fast-slow (activity), active-passive (activity), and hard-soft (potency).

Although there are significant changes in ratings along the progression from impoverishment to clarity, they are in a rather restricted range. Typically these ratings fall between 3 and 5 on the 7 point semantic differential scales.

The findings with respect to the scales loading on the evaluation factor are strongly confirmatory of Draguns's original results, i.e., increasing clarity is associated with positive evaluation. However, the findings with respect to the activity and potency factors are the opposite of Draguns's findings, i.e., as stimuli approach clarity they are rated as being more potent and more active. They are rated as being heavier, stronger, larger, and more tense.

For each of the nine scales producing significant trends, further analyses were undertaken. Following Keppel (1973), comparisons were made between ratings at each stage of clarity within each scale. These results are presented in Table 2. Perusal of these findings reveals that while increases in clarity are associated with positive evaluation, as well as more activity and potency, differences between the nature of the evaluation trends on the one hand, and the activity and potency trends, on the other are apparent. Among the evaluation scales quadratic and sometimes cubic trends are present along with linear trends. However, only one nonlinear trend is present among the activity and potency scales. This difference is graphically demonstrated in Figure 1, which contrasts representative trends for each of these two groupings.

Comparison of these two types of trend indicates a difference in the nature of the scales loading on the evaluation factor and those loading on the activity and potency factors. In the case of the former the first four stages of clarity are rated as being much the same; it is only in the last stage, where the stimulus is clear that there is a significant change in the ratings. For the activity and potency factors, however, it appears that with succeding stages of clarity, the stimuli become more dynamic, or active, and potent. Gradual changes on these factors, then, are not matched by similar changes in scales loading on the evaluation factor.

While there are differences between the two groups of scales in the nature of the trends observed, there is a conceptual similarity between them. Such a similarity is implied by Osgood and Suci (1955). They note that both the activity and potency factors "tend to be contaminated with a pervasive evaluativeness (Osgood 
Table 2

Nature of Trend for Semantic Differential Ratings and Comparison of Ratings Between Stages of Clarity

\begin{tabular}{|c|c|c|c|c|c|}
\hline \multirow{2}{*}{$\frac{\text { Scale }}{\text { Nice-Awful }}$} & \multirow{2}{*}{$\frac{\text { Trend }}{\text { Linear, Quadratic, Cubic }}$} & \multicolumn{4}{|c|}{ Between-Stage Comparison } \\
\hline & & $1-5 *$ & $2-5 *$ & $3-5^{*}$ & $4-5 *$ \\
\hline Clean-Dirty & Linear, Quadratic & $1-5^{*}$ & $2-5^{*}$ & $3-5 *$ & $4-5 *$ \\
\hline Pleasant-Unpleasant & Linear, Quadratic, Cubic & $1-5^{*}$ & $2-5 *$ & $3-5^{*}$ & $4-5^{*}$ \\
\hline \multirow[t]{2}{*}{ Good-Bad } & \multirow[t]{2}{*}{ Linear, Quadratic } & $1-5^{*}$ & $\begin{array}{l}2-5 * \\
2-4 \dagger\end{array}$ & \multirow[t]{2}{*}{$3-5 *$} & \multirow[t]{2}{*}{$4-5^{*}$} \\
\hline & & $1-3 *$ & $2-3 \dagger$ & & \\
\hline Important-Unimportant & Linear & $1-5 * *$ & $2-5 * *$ & $3-5 * *$ & $4-5 \dagger$ \\
\hline Tense-Relaxed & Linear & $1-5 \dagger \dagger$ & $\begin{array}{l}2-5^{*} \\
2-4 \dagger \dagger\end{array}$ & $3-5 * *$ & $4-5 \dagger$ \\
\hline Large-Small & Linear & $\begin{array}{l}1-5^{*} \\
1-4 \dagger \dagger \\
1-3 \dagger\end{array}$ & $2-5 \dagger$ & & $4-5+\dagger$ \\
\hline Heavy-Light & Linear & $\begin{array}{l}1-5^{* *} \\
1-4 \dagger \\
1-3^{* *}\end{array}$ & & & \\
\hline Strong-Weak & Linear, Quadratic & $\begin{array}{l}1-5 * \\
1-4 \dagger \dagger\end{array}$ & $2-5^{*}$ & $3-5^{*}$ & $4-5^{*}$ \\
\hline . & & $1-3 \dagger$ & $2-3 \dagger$ & & \\
\hline
\end{tabular}

and Suci, 1955, p. 338)," and that this tendency is in the direction of linking good-strong-active as opposed to bad-weak-passive.

With specific reference to the present study, then, as the stimuli approach clarity, they appear to become

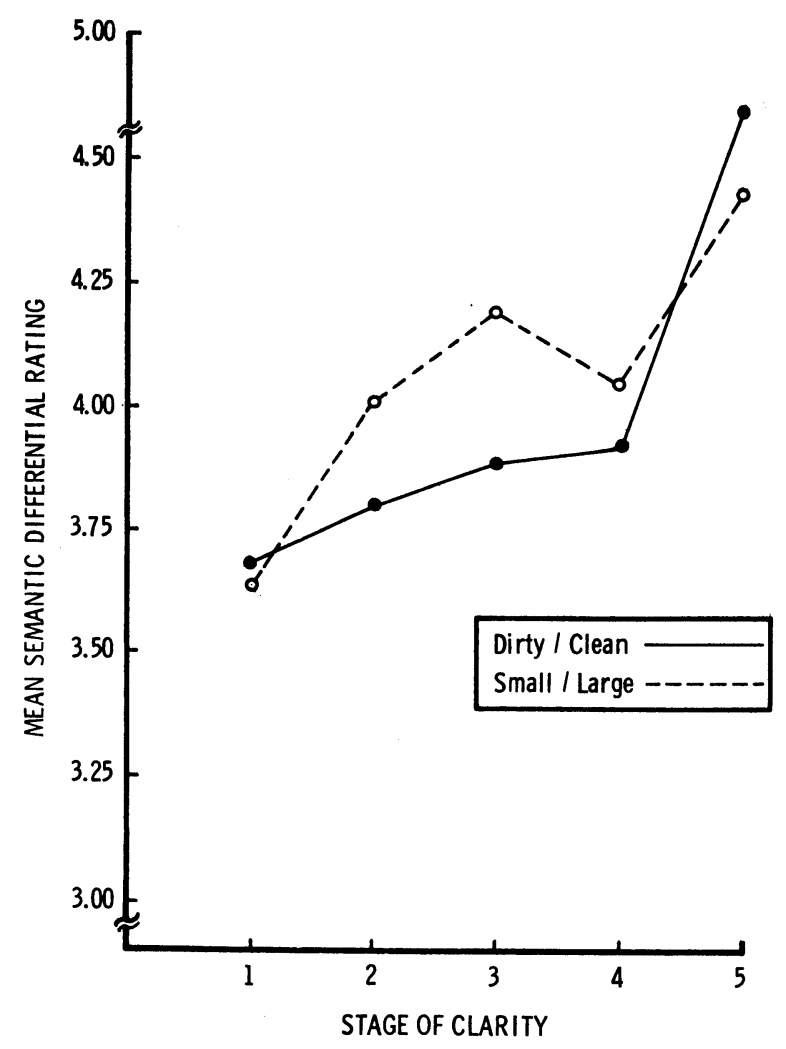

Figure 1. Comparison between ratings of pictorial stimuli on two semantic differential scales. more substantial and more tangible. Correlatively, they are rated more positively. The paucity of significant findings with respect to ratings on scales which load on the activity factor may be the result of the stimuli being judged. Such an explanation is suggested by Osgood, Suci, and Tannenbaum (1957). Factor analysis of semantic differential ratings, using a wider sampling of scales, of these stimuli might shed light on this issue.

The present study, then, presents findings that are to some degree discrepant with previously held views on the motivational nature of incomplete or impoverished stimuli. Further work is planned to investigate the factor structure of these stimuli, as well as to explore the relationship between the affective ratings of these stimuli and personality variables, e.g., sensation seeking.

Lastly, it should be noted that the slide method of presentation of these stimuli is quite feasible. Furthermore, it does not seem theoretically likely that this mode of presentation would be responsible for the results obtained.

\section{REFERENCES}

Beyn, E. S. Zhirmunskaya, E. A., \& Volkov, V. N. Electroencephalographic investigations in the process of recognizing images of objects during their tachistiscopic presentation-I. Neuropsychologia, 1967, 5, 203-217.

Draguns, J. G. Affective meaning of reduced stimulus input: a study by means of the semantic differential. Canadian Journal of Psychology, 1967, 21, 231-240.

Frohlich, W., \& Laux, L. Serielles Wahrnehmen, Aktualgenese, Informationsintegration and Orientierungsreaktion. Zeitschrift fur experimentelle und angewandte Psychologie, 1969, 16, 250-277.

Keppel, G. Design and Analysis. Englewood Cliff, N. J.: Prentice-Hall, 1973.

Osgood, C. E., \& Suci, G. J. Factor analysis of meaning. Journal of Experimental Psychology, 1955, 50, 325-338.

Osgood, C. E., Suci, G. J., \& Tannenbaum, P. H. The measurement of meaning. Urbana: University of Illinois Press, 1957.

(Received for publication September 29, 1974.) 